\title{
SOFTWARE COMO SERVIÇO: UM ESTUDO DE CASO
}

\section{SOFTWARE AS SERVICE: A CASE STUDY}

\author{
Núbia Caversan*E-mail: nubia.caversan@gmail.com \\ Andrea Lago da Silva*E-mail: deialago@hotmail.com \\ Luciana Torres Correia de Mello* E-mail: lucianatcmello@yahoo.com.br \\ *Universidade Federal de São Carlos (UFSCar), São Carlos, SP
}

Resumo: Este artigo analisa o processo de servitização em uma empresa de tecnologia de informação. Inicialmente foi realizada uma revisão de literatura, seguida de um estudo de caso na empresa de software. Observações diretas e entrevistas com os colaboradores envolvidos diretamente no processo foram realizadas, caracterizando motivações, mudanças e desafios. A partir da análise dos resultados, foi desenvolvido um checklist que auxilia as empresas na adoção de tal prática. Algumas ações são importantes na implantação da servitização: a revisão do portfólio de produtos e clientes; a preparação das equipes de linha de frente, envolvimento da gestão e liderança, a gestão de contratos e a gestão de melhorias.

Palavras-chave: Serviço. Software como Serviço. Servitização. Tecnologia da Informação.

Abstract: This article analyzes the servitization process in an information technology company. Initially, a literature review was carried out, followed by a case study in the software company. Direct observations and interviews with the collaborators directly involved in the process were conducted, characterizing motivations, changes and challenges. Based on the analysis of the results, a checklist was developed that helps companies to adopt this practice. Some actions are important when implementing servitization: a portfolio review of products and clients; preparing frontline teams, involving management and leadership, contract management and improvement management.

Keywords: Service. Software ss Service. Servitization. Information Technology.

\section{INTRODUÇÃO}

A maturidade tecnológica de produtos, a baixa rentabilidade e o fraco crescimento de mercados maduros e desenvolvidos têm levado as indústrias dos mais diversos setores a buscarem novas estratégias (MATTOS, 2012). No caso da servitização, esse processo é entendido como uma estratégia competitiva de diferenciação, utilizada quando uma empresa que tradicionalmente oferecia apenas produtos adiciona serviços à sua oferta ao cliente (BARNETT et al., 2013; NIE; KOSAKA, 2014), sendo uma base para criar novas fontes de receitas e lucros (OLIVA; KALLENBERG, 2003). 
Atualmente as empresas têm procurado se diferenciar das concorrentes por meio da inovação contínua, como forma de gerar sempre uma oferta com valor único para seus clientes, em que há uma tendência à comoditização, como padronização dos produtos ofertados (SOUSA; NOBREGA; SANTOS, 2014). Diversas empresas enxergam o processo de servitização como a evolução natural dos seus negócios, que as levam a oferecer serviços complementarmente ou adicionalmente a produtos. Outros executivos enxergam serviços como uma maneira óbvia de criar novas oportunidades. Para outros ainda, em indústrias mais maduras, serviços são interpretados como uma ferramenta de diferenciação, visando estender o ciclo de vida dos seus produtos e, consequentemente, evitar a falência de seus negócios (VANDERMERWE; RADA, 1988).

No entanto, pouco se discute acerca da mudança organizacional que uma empresa pode enfrentar durante a implementação de estratégias de servitização, os seus custos e benefícios financeiros posteriores (PETTIGREW; WOODMAN; CAMERON, 2001). Ainda, apesar de muitos dos protocolos necessários para se atingir uma oferta de serviços adequada já estarem disponíveis ou sendo desenvolvidos, existem falhas significativas nos mesmos (TURNER; BUDGEN; BRERETON, 2003), sobretudo no tocante a direcionamentos organizacionais que auxiliem os gestores a implantar a servitização em suas empresas.

No intuito de implementar uma estratégia de servitização de sucesso, uma empresa deve adaptar vários aspectos da sua estrutura organizacional e de processos (BAINES et al., 2009b; OLIVA; KALLENBERG, 2003). Assim, a transição de uma visão centrada em produtos para uma centrada em serviços ou em clientes segue sendo pouco compreendida e, continua a ser um conceito novo e complexo (AHAMED et al., 2013). Este artigo busca analisar o processo de servitização em uma empresa produtora de software, com o intuito de compreender motivações, mudanças e desafios decorrentes da implantação, a partir da visão dos envolvidos diretamente neste processo.

O artigo está estruturado da seguinte forma. A seção 1 de caráter introdutório, a seção 2 faz uma breve revisão de literatura sobre servitização, considerando os aspectos motivações e desafios (2.1) e, mudanças decorrentes do processo de servitização (2.2). A seção 3 expõe os procedimentos metodológicos da pesquisa, seguida pela seção 4 que apresenta o caso (4.1) e analisa a situação encontrada na 
empresa foco do estudo de caso realizado (4.2). Por fim, a seção 5 destaca as principais conclusões da pesquisa, limitações e sugestões para trabalhos futuros.

\section{REVISÃO BIBLIOGRÁFICA}

As primeiras definições do termo servitização surgiram por meio de estudos que se referiam a uma oferta de pacote de mercado mais ampla, com combinações focadas em bens, serviços, apoio, autosserviço e conhecimento, para agregar valor aos produtos essenciais (VANDERMERWE; RADA, 1988). É como uma inovação nos processos das empresas, as quais deixam de vender apenas produtos e passam a ofertar sistemas de produto e serviço, que se complementam e agregam valor um ao outro simultaneamente (BAINES et al., 2009b).

A expansão da oferta de serviços parte de motivações (GEBAUER; FRIEDLI, 2005), que podem ser entendidas como expectativas de resultados positivos (benefícios) proporcionados pela implantação da servitização em uma empresa. São observadas também barreiras cognitivas que podem inibir a realização da adição de serviços, uma vez que tal processo de transição muitas vezes resulta em um alto volume de serviços ofertados (GEBAUER; KREMPL; FLEISCH, 2008), e são tomados como desafios para a empresa que deseja passar por essa transformação. Tanto motivações como desafios podem atingir aspectos financeiros, estratégicos ou estarem relacionados ao marketing.

\subsection{Motivações e Desafios}

Para superarem o problema de manter seu crescimento em mercados saturados as empresas optam por transformar-se ou adotar estratégias de servitização (ULAGA; REINARTZ, 2011). As empresas podem se beneficiar de uma estratégia baseada em serviços de várias maneiras. Por exemplo, essa estratégia pode ajudar a conquistar a excelência na oferta de serviços, com sistemas de entregas e tecnologia mais eficientes (GRONROOS, 2004). Do ponto de vista do próprio cliente, manter uma excelência no nível de serviço acarretará maior satisfação percebida. 
Ao analisar o preço de um serviço, pode-se dizer que o mesmo varia entre limites mais amplos que os de bens de consumo e sofre maior influência de fatores estipulados subjetivamente pelo produtor e pela atribuição de valor do consumidor (SPILLER, 2011). Eles possuem maior margem de lucro que os produtos (SLACK, 2005). Isso pode ter como consequência maiores ganhos econômicos e receitas mais estáveis (GEBAUER; FRIEDLI, 2005; OLIVA; KALLENBERG, 2003).

É possível considerar que os serviços podem funcionar como uma forma de fidelização do cliente, criando barreiras à entrada, na medida em que se desenvolvem relacionamentos com estes (FITZSIMMONS; FITZSIMMONS, 2010; MARTINEZ et al., 2010; MATHIEU, 2001). O cliente passa a enxergar sua provedora de serviço como solucionadora das dificuldades encontradas, despertando uma expectativa de que poderá encontrar soluções para outras questões. Essa percepção surge a partir de uma relação de parceria que passou a existir entre ambos.

Outro motivador oriundo da oferta de serviços consiste em possíveis ganhos oriundos de estratégias de diferenciação (VANDERMERWE; RADA, 1988). Isso significa oferecer aos clientes algo que eles valorizam e que os concorrentes não têm. Com esse objetivo, as empresas passam a focar seus esforços na oferta de produtos ou serviços e tem a oportunidade de diferenciar-se em cada ponto onde ela entra em contato com o seu cliente, gerando uma vantagem competitiva (BAINES et al., 2007). Sendo assim, as empresas com pensamento criativo para a experiência de seus clientes com um produto ou serviço podem descobrir oportunidades para posicionar suas ofertas de forma que eles e os seus concorrentes nunca teriam pensado ser possível (MACMILLAN; MCGRATH, 1997).

Em contraponto às motivações para inserir a servitização dentro dos processos de uma empresa, há também desafios que essa conjuntura necessita atravessar para ter uma implantação satisfatória. São desafios inerentes à transformação exigida pelo pacote que integra produto e serviço, muitas vezes vistos como barreiras que dificultam a mudança de estratégia.

Definir uma estrutura organizacional que suporte também a oferta de serviços é um grande desafio em uma empresa manufatureira, já que o foco de suas áreas de vendas sempre esteve voltado apenas para produto (WISE; BAUMGARTNER, 1999). As empresas precisam estar preparadas para serem 
orientadas para serviços, centradas no cliente e com competências diferentes (SHEPHERD; AHMED, 2000). Estar centrada no cliente significa atender seus requisitos para criar ofertas de produtos e serviços que entreguem os resultados esperados, superiores a venda de produtos e serviços separadamente (SHEPHERD; AHMED, 2000).

As mudanças comportamentais internas são pré-condições para o sucesso de companhias que querem vender soluções (KUMAR; LEMON; PARASURAMAN, 2006). As mudanças devem estar bem alinhadas à percepção cultural dos colaboradores acerca da necessidade de transferir o foco de venda no produto, para uma entrega de oferta integrada (MARTINEZ et al., 2010). Isso demanda capital humano diferenciado (BEUREN et al., 2014). Um dos maiores desafios de se implementar uma estratégia de servitização é que a mesma liderança que desenvolveu um negócio orientado à produto de sucesso agora se torna um obstáculo no processo de servitização (NIE; KOSAKA, 2014).

A mudança organizacional envolve ainda aumento de responsabilidade dos participantes do processo (KUO, 2011). Estes passam a assumir atividades antes desempenhadas pelos próprios clientes (OLIVA; KALLENBERG, 2003; VANDERMERWE; RADA, 1988). Isso acontece porque, ao introduzir a venda integrada de produto e serviço, as empresas também precisarão considerar vários tipos de venda, vários serviços de manutenção de produto, e até os planos de logística reversa (KUO, 2011).

Outro desafio encontrado no processo de implantação da servitização que deve ser analisado é como compreender a complexidade do consumidor (MATTHYSSENS; VANDENBEMPT, 2008). Entender a mentalidade atual dos consumidores (BEUREN et al., 2014) requer que companhias exerçam uma boa gestão de seus clientes (KUMAR; LEMON; PARASURAMAN, 2006). É válido dizer que ampliar os serviços dentro das empresas parece ser um caminho para sobrepor - problema das necessidades cada vez mais complexa dos consumidores (GEBAUER; KREMPL; FLEISCH, 2008), mostrando ao cliente soluções das quais ele precisa, gerando a necessidade dos novos serviços.

O design e o desenvolvimento de serviços são diferentes do desenvolvimento do produto, basicamente pelo fato de que os serviços são intangíveis e heterogêneos, o que pode desencorajar empresas manufatureiras a 
expandirem o desenvolvimento de serviços, já que elas precisam considerar competir fora de seu domínio usual da competição em produtos e com rivais inesperados, por exemplo, seus próprios fornecedores e distribuidores (MATHIEU, 2001). As motivações e desafios foram sintetizados no Quadro 1.

Quadro 1 - Motivações e desafios

\begin{tabular}{|c|c|}
\hline Motivadores & Desafios \\
\hline $\begin{array}{l}\text { Excelência na oferta de serviços, custos e } \\
\text { sistemas de entrega e tecnologia } \\
\text { (GRONROOS, 2004) }\end{array}$ & $\begin{array}{l}\text { Foco na venda do produto / Pensamento no } \\
\text { sistema com foco no uso (BEUREN et al., } \\
\text { 2014; MARTINEZ et al., 2010; WISE; } \\
\text { BAUMGARTNER, 1999) }\end{array}$ \\
\hline $\begin{array}{l}\text { Maior margem de lucro / ganhos } \\
\text { econômicos / receita mais estável } \\
\text { (GEBAUER; FRIEDLI, 2005; OLIVA; } \\
\text { KALLENBERG, 2003; SLACK, 2005) }\end{array}$ & $\begin{array}{l}\text { Mudança comportamental interna (BEUREN } \\
\text { et al., 2014; KUMAR; LEMON; } \\
\text { PARASURAMAN, 2006; MARTINEZ et al., } \\
\text { 2010) }\end{array}$ \\
\hline $\begin{array}{l}\text { Fidelização do cliente (FITZSIMMONS; } \\
\text { FITZSIMMONS, 2010; MARTINEZ et al., } \\
\text { 2010; MATHIEU, 2001) }\end{array}$ & $\begin{array}{l}\text { Aumento de responsabilidade (KUO, 2011; } \\
\text { OLIVA; KALLENBERG, 2003; } \\
\text { VANDERMERWE; RADA, 1988) }\end{array}$ \\
\hline \multirow[t]{2}{*}{$\begin{array}{l}\text { Estratégia de diferenciação / vantagem } \\
\text { competitiva (BAINES et al., 2007; } \\
\text { VANDERMERWE; RADA, 1988) }\end{array}$} & $\begin{array}{l}\text { Mentalidade dos consumidores (BEUREN et } \\
\text { al., 2014; KUMAR; LEMON; } \\
\text { PARASURAMAN, 2006; MATTHYSSENS; } \\
\text { VANDENBEMPT, 2008) }\end{array}$ \\
\hline & $\begin{array}{l}\text { Desenvolvimento do serviço em paralelo ao } \\
\text { desenvolvimento do produto (ALMEIDA; } \\
\text { CAUCHICK MIGUEL; DA SILVA, 2011; } \\
\text { MATHIEU, 2001) }\end{array}$ \\
\hline
\end{tabular}

Fonte: elaborado pelos autores (2016)

\subsection{Mudanças}

As motivações para o processo de servitização envolvem mudanças em diversas áreas de uma empresa, como: pesquisa e desenvolvimento, aquisição, produção, vendas e marketing e serviços de pós-venda (AHAMED et al., 2013). Ou seja, a servitização implica em alterar seu modo de pensar e trabalhar, e também impacta seus consumidores e fornecedores, que também precisam exercer uma parte mais proativa durante o ciclo de vida do produto e serviço (VANDERMERWE; RADA, 1988). Não existem, entretanto, modelos específicos que abrangem questões referentes à servitização como um processo de mudança (MARTINEZ et al., 2010).

$\mathrm{O}$ alinhamento estratégico pode ser entendido como a integração entre as diferentes áreas da empresa como um todo no sentido de entender e implantar o 
conceito de provisão de serviço. É crucial que a empresa compartilhe a mesma linguagem e pensamento, permitindo que todos os colaboradores envolvidos na oferta de serviço pensem sob a ótica do cliente (MARTINEZ et al., 2010), especialmente quando a oferta de produto e serviço é simultânea. Esta alteração acarretará mudanças em muitos setores da empresa, que só serão possíveis, se alinhadas com a nova estratégia de negócios.

Estudos sobre a transição de bens de consumo para uma integração de bens e serviços propõe que novas formas de ofertas estão associadas com novos requisitos organizacionais (GALBRAITH, 2002). Consequentemente, a estrutura organizacional irá se diferenciar de acordo com o portfólio de serviços de cada negócio, assim como o tipo de consumidor, a sua disposição em participar no processo de criação de serviços e sua inclinação em investir na relação empresaconsumidor (GEBAUER; KREMPL; FLEISCH, 2008; KINDSTROM, 2010). Dessa forma, alterações nos contratos dos clientes, especialmente na categoria de negócios entre empresas (B2B) deverão contar com adaptações individuais, considerando atender as necessidades do mercado (KINDSTROM, 2010).

Dentre as mudanças necessárias durante o processo de servitização, os riscos estão entre as principais. A necessidade de um investimento a longo prazo no reconhecimento da marca, referindo-se na ameaça iminente de ineficiência e ineficácia durante o processo de transição é apontado como um grande risco para a empresa durante o processo de servitização (MATTHYSSENS; VANDENBEMPT, 2008).

A mentalidade cultural é um grande foco de mudança na inserção dos serviços como principal fonte de lucro para a companhia. Transformar a cultura de uma empresa de manufatura para uma empresa de serviços, sendo estes relacionados a produtos ou não, se baseia no fato de que, culturalmente, as pessoas vinculadas ao processo ainda pensam em produtos como a principal fonte de lucro (MARTINEZ et al., 2010). A mudança na mentalidade cultural também é observada na "rede de atores" como uma mudança prática no modo de interação fabricanteusuário e detenção de propriedade do produto (ARIENTE NETO et al., 2014).

O alinhamento de processos para apoiar 0 desenvolvimento requer mudanças nas operações para que a empresa alcance um nível adequado de ofertas integradas (MARTINEZ et al., 2010). No setor produção, devem-se 
reestruturar seus recursos entre suas fábricas, de acordo com capacidades e habilidades de colaboradores, considerando a necessidade de entrega de serviços para seus clientes (AHAMED et al., 2013).

\section{PROCEDIMENTOS METODOLÓGICOS}

Essa pesquisa classifica-se como exploratória, dado que o objetivo não é descrever ou identificar e explicar relações, mas sim compreender um dado fenômeno (YIN, 2001), no caso, a servitização em uma empresa do setor de tecnologia da informação. Outro aspecto importante a ser considerado é a abordagem do problema, nesse caso, pode ser classificada como qualitativa, que tem como objetivo examinar aspectos, em relação à sua interpretação em contextos específicos de investigação (KETOKIVI; CHOI, 2014).

O estudo foi desenvolvido em duas partes, onde na primeira foi realizado um levantamento bibliográfico sobre o tema servitização, abrangendo motivações, mudanças organizacionais e desafios. E na segunda parte, foi realizado um estudo de caso, na intenção de entender a interpretação de tais aspectos, tendo-os inseridos em um contexto prático e atual. Tratou-se, no estudo de caso, buscar a elaboração de teoria, investigando a já existente e o contexto, simultaneamente e de maneira balanceada (KETOKIVI; CHOI, 2014), posteriormente contrastando com o que foi encontrado na literatura.

Após o levantamento bibliográfico, na etapa do estudo de caso, buscou-se analisar o processo de servitização dentro de uma empresa de tecnologia de informação, produtora de software, fazendo possível identificar no processo, as motivações, mudanças e desafios do mesmo. Antes da realização do estudo de caso, especialistas do mercado foram consultados com o objetivo de validar o roteiro das entrevistas (VOSS; TSIKRIKTSIS; FROHLICH, 2002; YIN, 2001). As orientações principais para o estudo de caso, como as questões, os casos, os perfis entrevistados e o estilo de análise dos dados, e o roteiro de entrevistas foram inseridas no protocolo de estudo de caso (não anexos neste trabalho por falta de espaço) (EISENHARDT; BROWN, 1998; YIN, 2001).

No protocolo de pesquisa estão claras as duas questões principais que foram propostas para entendimento do todo: "Quais os principais benefícios e desafios do 
processo?" e "Como o processo ocorre em uma empresa do setor de tecnologia da informação?". E o roteiro de entrevista traçou os aspectos de identificação da empresa, caracterização dos entrevistados e as questões-chaves a eles indagadas para compreender o processo de servitização, que é o objetivo principal desse estudo. A entrevista aos colaboradores selecionados seguiu uma linha de questionamentos agrupados de acordo com aspectos pensados para atender ao objetivo proposto nessa pesquisa, como pode ser observado no Quadro 2.

Quadro 2 - Síntese do roteiro de entrevista

\begin{tabular}{|l|l|}
\hline $\begin{array}{c}\text { Categoria de } \\
\text { análise }\end{array}$ & \multicolumn{1}{c|}{ Questão } \\
\hline Benefícios & $\begin{array}{l}\text { • Quais os principais resultados esperados? Dê exemplos do que } \\
\text { vem ocorrendo aqui a curto e longo prazo. E em relação aos } \\
\text { resultados já obtidos? } \\
\text { - Quais os pontos de melhoria para o processo de servitização em } \\
\text { sua empresa? }\end{array}$ \\
\hline Mudanças & $\begin{array}{l}\text { - Você acredita que o processo de servitização é diferente em uma } \\
\text { empresa de software em relação a uma empresa de manufatura? } \\
\text { Descreva. } \\
\text { - Como o processo iniciou nessa empresa? } \\
\text { - Você acredita que seja possível utilizar a atual estrutura da } \\
\text { empresa, ou há a necessidade de uma reestruturação? } \\
\text { - Comente as principais mudanças. }\end{array}$ \\
\hline Desafios & $\begin{array}{l}\text { - Quais são os principais desafios? Dê exemplos do que vem } \\
\text { ocorrendo aqui. } \\
\text { - Quais as razões para um possível insucesso dessa estratégia? }\end{array}$ \\
\hline
\end{tabular}

Fonte: elaborado pelos autores (2016)

As entrevistas foram realizadas individualmente com sete colaboradores de diferentes níveis e funções da estrutura organizacional da empresa, conforme descrito mais detalhadamente no tópico a seguir. As mesmas tiveram duração estimada de 20 a 30 minutos durante os meses de julho e agosto de 2015. Além das entrevistas, foi realizada observação (participação em reuniões) e consulta a documentos da empresa (portais internos, apresentações e vídeos de especialistas e colaboradores da própria empresa). Após isso, elas foram transcritas, seguindo-se para análise e interpretação, com dados contrastados com a literatura revisada, buscando o cruzamento de diferentes fontes de evidência, que é fundamental para a validade de um estudo (VOSS; TSIKRIKTSIS; FROHLICH, 2002). 


\section{APRESENTAÇÃO E DISCUSSÃO DO ESTUDO DE CASO}

\subsection{Caracterização do estudo de caso}

A empresa alvo do estudo de caso é uma multinacional que atua no setor de tecnologia da informação com foco no desenvolvimento de software e hardwares. Trata-se de uma das líderes no mercado, possuindo no Brasil em torno de 900 colaboradores, treze filiais e faturamento médio de 25 bilhões de reais. $O$ desenvolvimento dessas tecnologias é realizado principalmente na matriz, nos Estados Unidos. No Brasil, possui plantas nos estados do Rio de Janeiro e São Paulo.

A empresa fornece soluções para empresas e consumidores finais, ou seja, tem foco B2B - Business to Business - e B2C - Business to Consumer. Os principais clientes B2C são consumidores de tecnologia móvel, como celulares e tablets, além de desktops e notebooks, que, no momento da aquisição desses hardwares, acabam adquirindo o software já instalado. Os clientes B2B no Brasil são bancos em sua grande maioria, grandes varejistas como B2w e Via Varejo, dentre outras multinacionais dos mais diversos setores, como automobilístico, energia, papel, petroquímica, mineração, siderúrgica e educação.

A própria empresa percebeu que a demanda por softwares estava migrando para soluções customizáveis e que a taxa de renovação da licença de seus produtos estava regredindo ano a ano. Foi assim que se percebeu a necessidade de ações para fidelizar clientes, com vistas a manter suas receitas constantes, aliada à constante busca por inovações e melhorias em seu portfólio, tão característica desse tipo de mercado. Nesse sentido, a decisão estratégica foi fornecer a atualização para o sistema mais recente de forma gratuita, passando a oferecer o software como serviço e não mais como produto, iniciando um processo de servitização. Neste caso, o usuário não pagaria para adquirir e sim para usá-lo (pagamento de uma licença anual), podendo customizá-lo da maneira como preferir. Com essa mudança, o sistema passaria a oferecer aplicativos em sua loja e estes poderão ser adicionados ao sistema de acordo com as preferências do usuário. Além disso, o mesmo pode ser acessado em qualquer dispositivo a partir da necessidade e comportamento de utilização dos usuários. 
Fizeram parte dessa mudança de estratégia os colaboradores envolvidos diretamente no processo de servitização, especialmente os pertencentes aos setores que exigiram adaptações e mudanças na empresa. Esses envolvidos possuem descrições explicitadas no Quadro 3 e foram alvo das entrevistas dessa pesquisa.

Quadro 3 - Perfil dos Entrevistados

\begin{tabular}{|c|c|c|}
\hline Cargo/Sigla & Formação & Escopo/Experiência no trabalho \\
\hline Diretor / (Dir) & Engenharia & $\begin{array}{l}\text { Experiência de } 18 \text { anos no mercado, sendo } 15 \text { na } \\
\text { indústria de tecnologia da informação, atuando em } 4 \\
\text { países diferentes. Há } 1 \text { ano e } 3 \text { meses na empresa } \\
\text { como diretor de produto, sendo responsável pelas } \\
\text { divisões B2B e B2C. Apesar de sua vasta } \\
\text { experiência, é seu primeiro contato com o processo } \\
\text { de servitização. }\end{array}$ \\
\hline $\begin{array}{l}\text { Gerente Sênior } \\
\text { de Produto } \\
\text { B2B / } \\
\text { (GerB2B) }\end{array}$ & $\begin{array}{l}\text { Administração } \\
\text { de Empresas }\end{array}$ & $\begin{array}{l}\text { Experiência de } 5 \text { anos em consultoria estratégica, } \\
\text { está na empresa há } 8 \text { anos e há } 5 \text { é responsável por } \\
\text { essa divisão de produto. }\end{array}$ \\
\hline $\begin{array}{l}\text { Gerente Sênior } \\
\text { de Produto } \\
\text { B2C / } \\
\text { (GerB2C) }\end{array}$ & Marketing & $\begin{array}{l}\text { Experiência anterior de } 4 \text { anos em uma } \\
\text { multinacional de bens de consumo e há } 3 \text { anos na } \\
\text { empresa como gerente de produto. Não teve contato } \\
\text { com o processo de servitização nesse ponto de sua } \\
\text { carreira. }\end{array}$ \\
\hline $\begin{array}{l}\text { Especialista de } \\
\text { produto / } \\
\text { (Espec1) }\end{array}$ & $\begin{array}{l}\text { Engenharia da } \\
\text { Computação com } \\
\text { Pós-graduação } \\
\text { em Marketing e } \\
\text { MBA em gestão } \\
\text { executiva }\end{array}$ & $\begin{array}{l}\text { Experiência anterior de } 2 \text { anos em uma empresa } \\
\text { fabricante de hardware, extremamente focada em } \\
\text { produção, já se deparou com demandas de } \\
\text { desenvolvimento de soluções e até mesmo serviços. } \\
\text { Está a } 3 \text { anos na empresa e aproximadamente } 1 \\
\text { ano e } 4 \text { meses nesse cargo. }\end{array}$ \\
\hline $\begin{array}{l}\text { Especialista } \\
\text { de produto / } \\
\text { (Espec2) }\end{array}$ & $\begin{array}{l}\text { Rede de } \\
\text { Computadores }\end{array}$ & $\begin{array}{l}\text { Está atualmente na sua segunda passagem pela } \\
\text { empresa, há } 1 \text { ano e meio, sendo que já trabalhou } \\
\text { nessa mesma função entre os anos de } 2011 \text { e } 2013 \text {. } \\
\text { Teve experiência em outra empresa do mesmo setor } \\
\text { que oferece produtos e serviços e é competidora } \\
\text { direta da empresa em questão, com um dos maiores } \\
\text { portfólios de software do mundo. }\end{array}$ \\
\hline $\begin{array}{l}\text { Analista de TI / } \\
\text { (ATI) }\end{array}$ & $\begin{array}{l}\text { Engenharia da } \\
\text { Computação }\end{array}$ & $\begin{array}{l}\text { Atualmente há } 1 \text { ano na empresa e no mesmo } \\
\text { cargo, possui experiência em consultoria na área de } \\
\text { suporte técnico, mas nunca teve contato com o } \\
\text { processo de servitização anteriormente. }\end{array}$ \\
\hline $\begin{array}{l}\text { Desenvolvedor } \\
\text { / (Desenv) }\end{array}$ & $\begin{array}{l}\text { Administração de } \\
\text { empresas com } \\
\text { especialização em } \\
\text { governança em TI } \\
\text { e gestão } \\
\text { estratégica }\end{array}$ & $\begin{array}{l}20 \text { anos de experiência no mercado de software, } \\
\text { trabalhando grande parte de sua vida em uma das } \\
\text { principais concorrentes da empresa no Brasil onde } \\
\text { vivenciou o processo de servitização e os principais } \\
\text { erros do processo. Está na empresa há } 4 \text { meses. }\end{array}$ \\
\hline
\end{tabular}

Fonte: Elaborado pelos autores (2016)

\subsection{Principais Resultados}

Revista Produção Online, Florianópolis, SC, v. 17, n. 1, p. 152-175, jan./mar. 2017. 
Para a análise, foram utilizadas as entrevistas realizadas com os colaboradores envolvidos no processo de servitização, buscando avaliar a percepção de cada um deles nos aspectos de motivações para implantar a servitização, desafios encontrados durante o processo, e as mudanças necessárias realizadas para sua efetivação.

\subsubsection{Motivações}

Ao serem questionados sobre as motivações da servitização, os colaboradores entrevistados falaram a respeito do valor percebido pelo cliente, como uma característica fundamental da oferta de serviços. Ao diferenciar sua oferta de acordo com a necessidade de seus clientes a empresa consegue exceder as expectativas de seus clientes. Ou seja, quando o serviço ofertado excede o nível de serviço acordado. A percepção está em consonância com o encontrado na literatura (GRONROOS, 2004), a respeito da excelência na oferta de serviços. Consequentemente, o valor percebido pelos clientes é maior, o que permite que o serviço seja ofertado a um valor acima do preço normalmente cobrado pelo produto, o que acaba por gerar mais receitas e lucros para empresa.

"Os clientes estão acostumados a comprar produtos e solicitarem
assistência caso dê errado. Você não tinha a necessidade de dar um
suporte de 24 horas. Agora, você passa a vender um serviço e no contrato
existe um nível de serviço acordado, ele estará em pleno funcionamento 90-
$95 \%$ do tempo. Quando o cliente contrata isso e você não entrega, você
perdeu o cliente. Então antes de vender a solução, você precisa ter alguém
especializado nisso e focado em atender qualquer demanda do cliente, foi
aí que a nossa empresa investiu em especialistas e em treinamento, eles
estão constantemente em campo, no cliente, dando suporte e recebendo
feedbacks, o que para gente é ótimo, vamos melhorando sempre mais"
(Desenv)

O quesito fluxo de caixa também é posto como um grande motivador oriundo desse processo de adoção da prática de servitização, confirmando o que foi encontrado na literatura (GEBAUER; FRIEDLI, 2005; OLIVA; KALLENBERG, 2003; SLACK, 2005), a maior margem de lucro dos serviços. O aumento dos lucros em uma empresa de tecnologia da informação que optou por ofertar softwares como serviço não é resultado somente do aumento de suas receitas, mas também da 
redução de seus custos a partir da utilização de novas tecnologias que permitem otimizar toda sua cadeia logística. Essa percepção pode ser observada na fala dos colaboradores.

\begin{abstract}
"A venda de software como produto inclui um bem físico, na maioria das vezes um $C D-R O M$, o que gera um custo de produção. Aquela caixinha que você compra, sabe? A oferta de serviços dilui esse custo, porque você tem o software na nuvem e o cliente só acessa esse software lá, o seu custo para cada licença vendida é muito menor, o que aumenta os seus lucros" (Espec2)
\end{abstract}

Outro importante motivador da servitização é a oferta de serviços criando barreiras de entrada, à medida que aumenta a fidelidade dos clientes e se desenvolve relações com estes. Observa-se também um aumento do custo de troca, que se refere ao estabelecimento de uma relação com o cliente que cria uma situação inconveniente para ele ao optar pela troca de fornecedor. Tal fenômeno foi apontado como um dos principais resultados para a empresa em questão, conforme citado na literatura (FITZSIMMONS; FITZSIMMONS, 2010; MARTINEZ et al., 2010; MATHIEU, 2001) e confirmado na fala de um dos gerentes. Ao fornecer um serviço único e customizado, a partir das necessidades de cada cliente, a empresa consegue fidelizá-lo ao se diferenciar de seus concorrentes, o que acaba por gerar uma maior retenção de clientes em longo prazo, como um de seus principais benefícios (LEVERIN; LILJANDER, 2006).

\footnotetext{
"Quando você customiza e oferta um software como serviço, inserindo nele solução para várias exigências do cliente de acordo com as necessidades dele, ele se transforma em um refém do seu serviço. A concorrência dificilmente conseguirá oferecer o mesmo serviço com os mesmos níveis acordados" (GerB2C)
}

A oferta de serviços também permite que a empresa estabeleça uma estratégia de diferenciação no contato com o seu cliente (LEVERIN; LILJANDER, 2006). Isso pode ocorrer desde a percepção por parte do cliente da necessidade do serviço, permitindo que a mesma trace estratégias rentáveis construídas com base na diferenciação e posicione suas ofertas de forma única, o que acaba por gerar um potencial para aumentar suas receitas. Tal resultado foi observado no caso estudado, como explicitado na fala de um dos colaboradores.

"Quando você oferece pro cliente algo que ele não vai encontrar em nenhum outro fornecedor, você consegue se diferenciar, ele vai pagar $o$ 
quanto for para ter aquilo. Por isso é importante preparar os seus vendedores, eles precisam ser pessoas extremamente qualificadas para conseguir ofertar todos os benefícios da solução de acordo com a necessidade do cliente" (Desenv)

\title{
4.2.2 Mudanças
}

No início das entrevistas, foi questionado à empresa sobre as mudanças internas necessárias e também na estratégia, para a implantação do processo de servitização. Os entrevistados mencionaram uma principal, as pessoas. Todos eles alegaram que inserir a filosofia de oferta de produtos e seus benefícios, sendo a nova estratégia da organização, é um desafio constante, principalmente para colaboradores que tem contato direto com clientes e tem como escopo de trabalho convencê-los que o produto agora ofertado como serviço é a solução ideal para atender suas demandas. A constante mudança e preparo da equipe para o processo é descrita por um dos entrevistados.

\begin{abstract}
"O nosso processo de servitização teve início com uma atualização da estrutura organizacional, vieram pessoas mais novas com maior conhecimento em serviços. Ademais, mudou o ciclo de P\&D e a maneira como pedíamos a aprovação do Capex para inovação, que passaram a ser constantes, para isso passamos a ter centros globais de inovação." (GerB2B)
\end{abstract}

Em uma empresa de software, a grande maioria de suas vendas era oriunda de contratos com empresas e renovação de licenças a cada ciclo de vendas e/ou lançamento de novos produtos. Com o processo de servitização, ocorreram mudanças nos contratos, que ficam muito mais complexos devido à abrangência de todas as características e funções do serviço ofertado. O principal desafio nesse caso é abranger a customização e a flexibilidade do serviço e garantir um nível de serviço que atenda as expectativas do cliente, tendo isso sido definido a priori contratualmente. Um dos entrevistados caracterizou as mudanças contratuais necessárias durante o processo de servitização.

\footnotetext{
"Os contratos têm muitos degraus para subir dentro da oferta de serviço,
} 
então quando você vendia um produto era um único produto, a partir da oferta do serviço, os contratos passaram a ser muito mais customizados e muito mais minuciosos. Os preços passaram a ser muito mais tabelados também, de acordo com o serviço oferecido e o nível de serviço ofertado" (ATI)

Em relação aos riscos percebidos no processo para a empresa de tecnologia que passa a ofertar seus softwares como serviço e não mais como produto, os entrevistados apontaram mudanças significativas em alguns riscos como a não adaptação interna à cultura de serviços. Os colaboradores podem sentir-se desmotivados com a mudança decorrente do processo, o que pode afetar a força de trabalho da empresa como um todo. Também se o serviço ofertado não for superior ao produto anteriormente disponibilizado, a empresa pode denegrir a imagem de sua marca; o serviço ofertado pode não atender as expectativas do cliente, tendo especificações piores ao produto anteriormente ofertado, ou ter um custo muito alto. Porém, as principais mudanças nos riscos apontados pelos entrevistados são a mudança de mentalidade dos colaboradores, que também é o principal desafio para a gestão, e o risco financeiro. Esse está explicitado na fala de um dos colaboradores.

"É um movimento que fez as empresas perceberem que é melhor ter uma receita constante do que em uma única vez sem a recorrência da receita. Tem empresas que estão ganhando dinheiro com isso e empresas que estão perdendo dinheiro com isso - o fato de terem muitos produtos no portfólio e nem sempre escolher o melhor produto para vender como serviço" (Desenv)

A mudança na cultura é outro fator importante no processo. A maneira como um serviço é produzido e ofertado difere muito da oferta de produtos, o que requer uma mudança cultural dentro da empresa. Essa mudança foi apontada por vários entrevistados como o principal desafio para a gestão. O diretor responsável pela área foi incisivo ao falar desse aspecto.

\footnotetext{
"Muitas pessoas não se adaptaram ao novo modelo e foram substituídas para que o processo pudesse ser satisfatório. Funcionários que antes eram orientados a vender produtos específicos para clientes e focados somente em assistências técnicas pontuais, atualmente mantém contato direto com o cliente durante todo o período de contrato do serviço" (Dir)
} 
A afirmação do diretor da área sobre a preparação da sua força de vendas para que essa seja capaz de oferecer as soluções ideais para seus clientes converge para o mesmo desafio encontrado na literatura (KUMAR; LEMON; PARASURAMAN, 2006; MARTINEZ et al., 2010), uma vez que o aumento da força de vendas está diretamente relacionado ao menor controle de seus funcionários. No entanto, a preocupação em qualificá-los de maneira adequada e prepará-los para que a oferta seja realizada de maneira adequada pode ser interpretada como uma possível solução desse problema (BATT, 2000).

"A partir do momento em que você precisa oferecer e vender um serviço para outra empresa ou cliente, você precisa preparar sua força de vendas, é complicado. Você precisa de funcionários dedicados a clientes o tempo todo, e funcionários que os convençam que essa é a melhor solução. Além de aumentar sua força de vendas, você precisa qualificá-la para o serviço" (Espec1)

\subsubsection{Desafios}

Quando questionados sobre os desafios encontrados durante o processo de servitização, com pedido de exemplificação, os colaboradores citaram a dificuldade de desvincular o pensamento das pessoas de que produtos são a principal fonte de lucro da empresa. Esse é um fenômeno apontado por Martinez et al. (2010) na literatura, uma vez que a intangibilidade do serviço é a causa raiz do problema, e também gera insegurança no cliente em adquirir algo não palpável. No caso de software como serviço, o processo passa pelo mesmo desafio, uma vez que, apesar de softwares serem intangíveis em sua essência, o processo de aquisição do mesmo sofreu alterações, como descrito por um dos entrevistados.

\footnotetext{
"Quando o cliente comprava o nosso software, ele se dirigia a uma loja adquiria uma embalagem com um disquete ou um CD-ROM, chegava em sua casa e instalava o produto no seu dispositivo. Essa é a principal diferença, o cliente adquiria algo palpável, apesar do produto em si ser algo intangível. Hoje ao adquirir o software como serviço, o cliente só adquire o direito de acessa-lo, tudo está na nuvem, ele se registra e acessa, mas não tem nada de palpável nisso, muitas vezes o cliente não enxerga o serviço como algo adquirido, ele sente falta disso" (Desenv)
}

Para obtenção dos benefícios, deve haver preocupação por parte da empresa em motivar seus colaboradores para que os mesmos se adaptem ao processo, 
incentivando uma mudança comportamental, conforme sugerido na literatura (BEUREN et al., 2014; KUMAR; LEMON; PARASURAMAN, 2006; MARTINEZ et al., 2010). No caso da empresa estudada, a liderança realizou um trabalho de preparação de seus funcionários, com treinamentos específicos para cada time, como vendas, especialistas e gestão/liderança. A liderança também desempenhou uma função crucial, uma vez que a empresa investiu em capacitação no exterior para os principais líderes do processo para que estes se capacitassem a partir de experiências ao redor do mundo e pudessem transmitir a nova filosofia da empresa para suas respectivas equipes, recebendo constantes feedbacks. A empresa deve focar em selecionar empregados com habilidades gerais elevadas e investir em treinamentos, uma vez que essa combinação resulta em uma empresa com uma força de trabalho habilidosa e capaz de aprender continuamente com o dia-a-dia do trabalho (BATT, 2000).

\begin{abstract}
"Ao se deparar com qualquer mudança a gestão se preocupa com as pessoas, antes de mais nada. No processo de servitização aqui dentro, não foi diferente, foi muito difícil inserir essa mentalidade na cabeça de colaboradores que já trabalhavam com a oferta do mesmo produto há décadas. Surgem dúvidas sobre o sucesso da estratégia, as pessoas ficam receosas, é natural, mas como líderes precisamos motiva-los, com treinamentos, palestras e casos de sucesso do processo. Infelizmente, muitas pessoas mais seniores não se adaptaram a realidade mais dinâmica de serviços e acabaram sendo substituídas por profissionais mais capacitados para trabalhar nessas condições" (Dir)
\end{abstract}

É importante ressaltar que também é apontado como um dos principais desafios do processo de servitização, a necessidade de que cada setor assuma responsabilidade pela definição de quais produtos deve ser ofertado como serviços, o que pode determinar o sucesso ou o fracasso do processo, uma vez que se deve realizar uma análise do mercado e aderência de seus consumidores a serviços ao invés de produtos.

\footnotetext{
"O nosso processo de servitização teve início com uma atualização da estrutura organizacional, vieram pessoas mais novas com maior conhecimento em serviços. Mudou-se o time de vendas, a forma de vender, a forma da oferta, a equipe teve que estar mais preparada para oferecer soluções cada vez mais customizadas e flexíveis para os nossos clientes" (GerB2B)
}

Para suportar a mudança de portfólio, alguns autores (GEBAUER; KREMPL; FLEISCH, 2008; KINDSTROM, 2010) apontam que a estrutura organizacional deve 
se diferenciar de acordo com cada negócio, assim como o tipo de consumidor, a sua disposição em participar no processo de criação de serviços e sua inclinação em investir na relação empresa-consumidor. No caso aqui apresentado, a mentalidade dos consumidores foi apontada como um desafio. Durante a entrevista alguns colaboradores afirmaram que a preparação adequada de pessoas em contato direto com o cliente é um fator crucial do processo. O consumidor precisa ser preparado para adquirir serviços ao invés de bens.

"A oferta de serviços se tornará uma tendência, principalmente pela questão de contenção de custos. Ficará na cabeça deles, que não querem mais ter alguma coisa. Eles vão preferir contratar alguma coisa, representando um menor custo, um menor investimento" (Espec1)

Os depoimentos também apontam como um dos principais desafios, a questão do desenvolvimento do serviço, que passa a ser constante e de acordo com feedbacks de clientes e melhorias observadas por especialistas no dia-a-dia. A área de pesquisa e desenvolvimento deve estar constantemente focada em inovações tecnológicas aplicadas a negócios que as demandam, com o intuito de atender as necessidades do consumidor e consequentemente, suas expectativas dentro do tempo esperado (AHAMED et al., 2013). Dessa forma, a empresa segue esse processo, com a criação de novos departamentos focados em constante inovação. E a complexidade do processo, no entanto, se deve ao fato de que as soluções ofertadas são customizadas de acordo com a necessidade do cliente, e essa é constantemente alterada.

"É raro ofertar a mesma solução para dois clientes diferentes, o volume de serviços e o nível acordado são sempre estabelecidos de acordo com as necessidades de cada um, o que aumenta o volume de diferentes serviços e exige uma equipe de desenvolvimento flexível e treinada" (Dir)

\section{CONSIDERAÇÕES FINAIS}

Reconhecendo a necessidade de desenvolver aspectos inovadores frente ao ambiente manufatureiro, a servitização tem se destacado dentre outras práticas de diferenciação, visto que permite uma empresa obter benefícios nos aspectos econômico, ambiental e social. É como uma inovação nos processos das empresas, as quais deixam de vender apenas produtos e passa a ofertar sistemas de produto $\mathrm{e}$ 
serviço (BAINES et al., 2009a), visando à satisfação do cliente, como também a distinção em relação aos concorrentes por assim demonstrar que o querer do cliente foi considerado (PIMENTEL, 2011).

Esse estudo permitiu identificar as motivações, mudanças necessárias e desafios encontrados no processo de servitização de uma empresa de tecnologia da informação. As possíveis melhorias de projeto de serviço estão relacionadas às operações de manutenção e reprocessamento, e como consequência podem reduzir custos de manutenção, reparo e reprocessamento (CALVILHO et al., 2014). A empresa estudada conseguiu reduzir custos de manutenção, reparo e processamento, quando passou a oferecer seu "produto" como um "serviço" ao cliente, facilitando o acesso a ele, como às atualizações, por meio da Internet.

De um modo geral, a empresa percebeu uma reação positiva dos clientes e consumidores à oferta de softwares como serviço, como também o processo de servitização, em curto prazo, com o funcionamento de acordo com o esperado, apesar dos desafios expostos, como a preparação interna da empresa. Ainda assim, a preocupação frequente com as necessidades do cliente e suas respectivas demandas podem ser apontadas como os principais fatores de sucesso do processo.

A ideia de proporcionar a entrega do software como serviço não é uma prática nova, na verdade, surgiu antes dos próprios computadores com a IBM (SULTAN, 2014). Entretanto, para evoluir na servitização, algumas recomendações podem ser oferecidas, partindo da análise do caso em questão, que é uma organização multinacional de desenvolvimento de hardwares e softwares. As recomendações estão baseadas nos três aspectos que foram considerados na análise, que são motivações, mudanças e desafios. A partir destas foi possível propor um checklist para direcionar empresas no processo de implantação da servitização, como segue na Figura 1.

Figura 1 - Checklist para processo de servitização

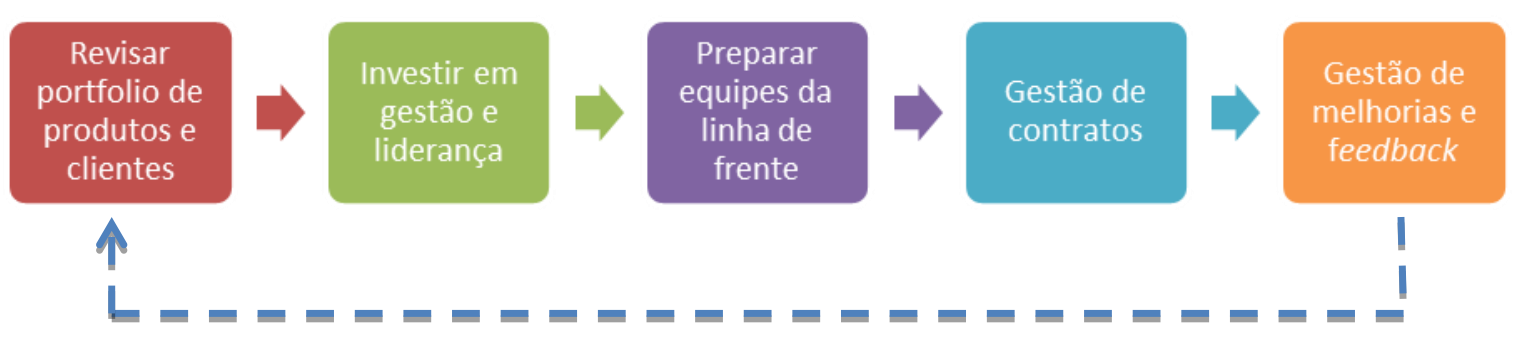

Revista Produção Online, Florianópolis, SC, v. 17, n. 1, p. 152-175, jan./mar. 2017. 
Fonte: elaborado pelos autores (2016)

A primeira fase do processo de servitização em uma empresa de tecnologia de informação é a revisão de seu portfólio de produtos, concomitantemente à sua carteira de clientes, com o intuito de identificar possíveis demandas de software como serviços e assim, as oportunidades de servitização. Uma vez identificada a demanda por soluções em termos de software como serviço, a empresa deve iniciar o processo a partir de investimentos na gestão e liderança. Isso porque a mudança cultural foi apontada como principal desafio e nesse caso os líderes serão responsáveis por conduzir o processo de servitização de maneira eficaz em toda a empresa, a partir de uma gestão bem executada do processo.

A oferta de serviços consiste em um contato mais intenso com os clientes. $O$ contato que anteriormente só ocorria no momento da venda e em assistências técnicas esporádicas passa a ser constante e muito mais próximo. Isso exige a preparação dos times a partir de treinamentos e boa gestão da liderança, que deve se preocupar com a mudança de mentalidade de seus respectivos times e gestão desses resultados. O processo de servitização também inclui a formalização de prestação de serviços a partir de contratos, que devem conter níveis de serviços acordados explicitados, duração do contrato, valores acordados, além da descrição da solução adquirida, ou seja, quais serviços estão inclusos no contrato.

A gestão de melhorias e inovações é um diferencial do processo de servitização. A partir do maior contato com o cliente oriundo da oferta de serviços a empresa tem acesso a feedbacks constantes e coleta de melhorias em campo, o que é possível graças a times de vendas e especialistas alocados junto a clientes. No entanto, a gestão dessas melhorias deve ser responsabilidade de equipes dedicadas, que devem analisá-las e implementá-las de acordo com uma matriz de priorização. Essa matriz deve levar em conta a facilidade de implementação versus o benefício de cada uma delas, o que requer a preparação de profissionais em termos técnicos para atender essas demandas e de gestão, uma vez que devem ser capazes de identificar oportunidades de melhorias que gerem, de fato, resultados significantes para a empresa.

Vale salientar que as empresas de tecnologia de informação prezam muito pelo sigilo de suas informações. Isso resultou em uma barreira de acesso e também 
não permitiu a divulgação de informações relacionadas às especificações técnicas das ofertas da empresa e aprimoramento das especificações dos softwares.

Para estudos futuros recomenda-se uma análise do processo de servitização em outras empresas de tecnologia, uma vez que a realização de outro caso poderia enriquecer a proposta de análise e o próprio checklist, mas devido a restrições de acesso e tempo não foram possíveis neste estudo. Por se tratar de um caso único as limitações, já são elucidadas por Yin (2001) no sentido de que um estudo de caso único é especialmente apropriado quando ele representa o caso decisivo ao testar uma teoria bem-formulada, utilizado para determinar se as proposições de uma teoria são corretas ou se algum outro conjunto alternativo de explanações pode ser mais relevante (YIN, 2001).

Novos estudos também deveriam abordar indicadores de desempenho e números resultantes do processo de servitização, a partir da análise de resultados reais de empresas estudadas, uma vez isso fortaleceria e traria mais elementos para o estudo exploratório qualitativo aqui apresentado. Esse artigo analisa uma empresa de capital aberto, que já disponibiliza seus resultados anuais para os acionistas, o que facilitaria a obtenção destes dados e a sua comparação com números de outras empresas do setor de tecnologia de informação, e fortaleceria os resultados da pesquisa.

\section{REFERÊNCIAS}

AHAMED, Z. et al. Organizational factors to the effectiveness of implementing servitization strategy. Journal of Service Science and Management, v. 6, s/n, p. 177-185, 2013. http://dx.doi.org/10.4236/jssm.2013.62018

ALMEIDA, L.; CAUCHICK MIGUEL, P.; DA SILVA, M. T. Uma revisão da literatura sobre "servitização": bases para a proposição de um modelo conceitual de decisão. Exacta, v. 9, n. 3, p. 339-354, 2011. http://dx.doi.org/10.5585/Exacta.v9i3.3115

ARIENTE NETO, R. et al. Elementos integrantes de um sistema produto-serviço como potencial para alcançar um desenvolvimento sustentável: bibliometria e análise de conteúdo. Produção Online, v. 14, n. 3, p. 914-938, 2014. http://dx.doi.org/10.14488/16761901.v14i3.1566

BAINES, T. et al. Towards an operations strategy for product-centric servitization. International Journal of Operations \& Production Management, v. 29, n. 5, p. 494-519, 24 abr. 2009a. http://dx.doi.org/10.1108/01443570910953603 
BAINES, T. S. et al. State-of-the-art in product-service systems. Proceedings of the Institution of Mechanical Engineers, Part B: Journal of Engineering Manufacture, $v$. 221, n. 10, p. 1543-1552, 2007. http://dx.doi.org/10.1243/09544054jem858

BAINES, T. S. et al. The servitization of manufacturing: a review of literature and reflection on future challenges. Journal of Manufacturing Technology Management, v. 20, n. 5, p. 547-567, 2009b. http://dx.doi.org/10.1108/17410380910960984

BARNETT, N. J. et al. Servitization: is a paradigm shift in the business model and service enterprise required? Strategic Change, v. 22, p. 145-156, 2013.

http://dx.doi.org/10.1002/jsc.1929

BATT, R. Managing customer services: human resource practices, turnover, and sales growth. Academy of Management Journal, v. 45, n. 3, p. 587-597, 2000.

http://dx.doi.org/10.2307/3069383

BEUREN, F. H. et al. Análise de conteúdo de publicações em sistemas produto- serviço.

Produção Online, v. 14, n. 1, p. 31-57, 2014. http://dx.doi.org/10.14488/1676-

1901.v14.i1.1405

CALVILHO, E. M. et al. Serviços agregados ao produto de um fabricante de equipamentos para a indústria petrolífera: o PSS. Produção Online, v. 14, n. 3, p. 972-996, 2014.

http://dx.doi.org/10.14488/1676-1901.v14i3.1581

EISENHARDT, K. M.; BROWN, S. L. Competing on the edge: strategy as structured chaos. Long Range Planning, v. 31, n. 5, p. 786-789, 1998. http://dx.doi.org/10.1016/S0024$\underline{6301(98) 00092-2}$

FITZSIMMONS, J. A.; FITZSIMMONS, M. J. Administração de serviços: operações, estratégia e tecnologia da informação. 6. ed. Porto Alegre: Bookman, 2010.

GALBRAITH, J. R. Organizing to deliver solutions. Organizational Dynamics, v. 31, n. 2, p. 194-207, 2002. http://dx.doi.org/10.1016/S0090-2616(02)00101-8

GEBAUER, H.; FRIEDLI, T. Behavioral implications of the transition process from products to services. Journal of Business \& Industrial Marketing, v. 20, n. 2, p. 70-78, 2005. http://dx.doi.org/10.1108/08858620510583669

GEBAUER, H.; KREMPL, R.; FLEISCH, E. Service development in traditional product manufacturing companies. European Journal of Innovation Management, v. 11, n. 2, p. 219-240, 2008. http://dx.doi.org/10.1108/14601060810869875

GRONROOS, C. Marketing: gerenciamento e serviços. 2. ed. Rio de Janeiro: Campus, 2004.

KETOKIVI, M.; CHOI, T. Renaissance of case research as a scientific method. Journal of Operations Management, v. 32, n. 5, p. 232-240, 2014.

http://dx.doi.org/10.1016/j.jom.2014.03.004

KINDSTROM, D. Towards a service-based business model - key aspects for future competitive advantage. European Management Journal, v. 28, n. 6, p. 479-490, 2010. http://dx.doi.org/10.1016/j.emj.2010.07.002 
KUMAR, V.; LEMON, K. N.; PARASURAMAN, A. Managing customers for value: an overview and research agenda. Journal of Service Research, v. 9, n. 2, p. 87-94, 2006. http://dx.doi.org/10.1177/1094670506293558

KUO, T. C. Simulation of purchase or rental decision-making based on product service system. The International Journal of Advanced Manufacturing Technology, v. 52, n. 912, p. 1239-1249, 2011. http://dx.doi.org/10.1007/s00170-010-2768-2

LEVERIN, A.; LILJANDER, V. Does relationship marketing improve customer relationship satisfaction and loyalty? International Journal of Bank Marketing, v. 24, n. 4, p. 232-251, 2006. http://dx.doi.org/10.1108/02652320610671333

MACMILLAN, I. C.; MCGRATH, R. G. Discovering new points of differentiation. Harvard business review, v. 75, n. 4, 1997.

MARTINEZ, V. et al. Challenges in transforming manufacturing organisations into product-service providers. Journal of Manufacturing Technology Management, v. 21, n. 4, p. 449-469, 2010. http://dx.doi.org/10.1108/17410381011046571

MATHIEU, V. Product services: from a service supporting the product to a service supporting the client. Journal of Business \& Industrial Marketing, v. 16, n. 1, p. 39-61, 2001. http://dx.doi.org/10.1108/08858620110364873

MATTHYSSENS, P.; VANDENBEMPT, K. Moving from basic offerings to value-added solutions: Strategies, barriers and alignment. Industrial Marketing Management, v. 37, n. 3, p. 316-328, 2008. http://dx.doi.org/10.1016/j.indmarman.2007.07.008

MATTOS, B. L. Impacto da Servitização no modelo de negócio de empresas manufatureiras: o caso Scania. 2012. 156 f. Dissertação (Mestrado em Administração) Fundação Getúlio Vargas, São Paulo, 2012. Disponível em: http://bibliotecadigital.fgv.br/dspace/handle/10438/10284

NIE, Y.; KOSAKA, M. A new perspective on leadership for achieving servitization of business. Journal of Management Research, v. 6, n. 4, p. 50, 2014. http://dx.doi.org/10.5296/jmr.v6i4.6088

OLIVA, R.; KALLENBERG, R. Managing the transition from products to services. International Journal of Service Industry Management, v. 14, n. 2, p. 160-172, 2003. http://dx.doi.org/10.1108/09564230310474138

PETTIGREW, A. M.; WOODMAN, R. W.; CAMERON, K. S. Studying organizational change and development: challenges for future research. Academy of Management Journal, v. 44, n. 4, p. 697-713, 2001. http://dx.doi.org/10.2307/3069411

PIMENTEL, A. R. A. Servitization : uma proposta de modelo. 2011. 72 f. Dissertação (Mestrado em Engenharia e Gestão Industrial) - Universidade de Aveiro, Aveiro, 2011.

SHEPHERD, C.; AHMED, P. K. From product innovation to solutions innovation: a new paradigm for competitive advantage. European Journal of Innovation Management, v. 3, n. 2, p. 100-106, 2000. http://dx.doi.org/10.1108/14601060010322293

SLACK, N. Operations strategy: will it ever realize its potential? Gestão \& Produção, v. 12, n. 3, p. 323-332, 2005. http://dx.doi.org/10.1590/S0104-530X2005000300004 
SOUSA, E. A.; NOBREGA, K. C.; SANTOS, K. A. S. Servitização: a crescente importância da oferta de serviços na indústria. In: Simpósio da Administração da Produção, Logística e Operações Internacionais, 2014, São Paulo. Anais...São Paulo: Fundação Getúlio Vargas, 2014.

SPILLER, S. A. Opportunity cost consideration. Journal of Consumer Research, v. 38, n. 4, p. 595-610, 2011. http://dx.doi.org/10.1086/660045

SULTAN, N. Servitization of the IT Industry: The Cloud Phenomenon. Strategic Change, v. 23, n. 3, p. 375-388, 2014. http://dx.doi.org/10.1002/jsc.1983

TURNER, M.; BUDGEN, D.; BRERETON, P. Turning software into a service. Computer, v. 36, n. 10, p. 38-44, 2003.

ULAGA, W.; REINARTZ, W. J. Hybrid offerings: how manufacturing firms combine goods and services successfully. Journal of Marketing, v. 75, n. 6, p. 5-23, 2011.

http://dx.doi.org/10.1509/jm.09.0395

VANDERMERWE, S.; RADA, J. Servitization of business: adding value by adding services. European Management Journal, v. 6, n. 4, p. 314-324, 1988. Disponível em < http://www.scopus.com/inward/record.url?eid=2-s2.0-1642608922\&partnerlD=tZOtx3y1>

VOSS, C.; TSIKRIKTSIS, N.; FROHLICH, M. Case research in operations management.

International Journal of Operations \& Production Management, v. 22, n. 2, p. 195-219, 2002. http://dx.doi.org/10.1108/01443570210414329

WISE, R.; BAUMGARTNER, P. The new profit imperative in manufacturing. Harvard Business Review, October, p. 133-142, 1999.

YIN, R. K. Estudo de caso: planejamento e métodos. 3. ed. Porto Alegre: Bookman, 2001.

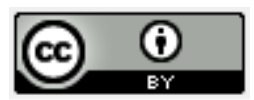

Artigo recebido em 24/03/2016 e aceito para publicação em 18/05/2016

DOI: http://dx.doi.org/10.14488/1676-1901.v17i1.2401 